\title{
AIRWAY OBSTRUCTION WITH CUFFED FLEXOMETALLIC TRACHEAL TUBES
}

\author{
R. Bachand and G. Fortin
}

\section{INTRODUCTION}

ARMoured latex TRACHEAL tubEs are used for patients in uncommon postures, the aim being to provide a safer airway. Recently, using this kind of tube, we have been confronted with an unusual complication.

\section{Report of a Case}

A twenty-one-year-old diabetic male patient was anaesthetized for hypophysectomy in an attempt to arrest or improve a progressive retinopathy.

Pre-operative assessment of physical status revealed a patient in a good general state of health, notwithstanding his diabetes. Premedication consisted of meperidine hydrochloride $50 \mathrm{mg}$ and atropine $0.4 \mathrm{mg}$ given intramuscularly one hour before operation.

When he arrived in the operating room, the patient was conscious, well oriented and adequately sedated. Anaesthesia was induced with thiopentone and succinylcholine chloride by the usual intravenous route of administration. The glottic area, vocal cords and proximal portion of the trachea were well visualized by laryngoscopy and were considered free of gross pathology. Intubation was performed atraumatically with a latex tube incorporating an imbedded metal spiral coil to prevent kinking and an inflatable cuff.

Before insertion, the tracheal tube was apparently sound in all respects; preliminary inflation of the cuff did not reveal potential abnormalities. Following tracheal intubation, the cuff was inflated concomitantly with positive pressure ventilation to the limit of minimum occlusive pressure compatible with an atraumatic airtight seal. Following intubation, ausculatation revealed identical bilateral breath sounds with clinically normal bilateral lung compliances. Anaesthesia was maintained with nitrous oxide and oxygen in a proportion of 5:2 litres per minute supplemented by Innovar. Relaxation adequate for controlled ventilation was obtained by the administration of repeated doses of d-tubocurarine. Controlled ventilation was maintained with an Ohio volume cycled anaesthesia ventilator at a minute volume of $8,400 \mathrm{ml}$.

The patient was postured with the head, the tracheal tube and breathing tubes being firmly immobilized and restrained by adhesive tape. As the transphenoidal surgical approach utilized in this case involves the accumulation of blood in the

From The Department of Anaesthesia, School of Medicine, University of Montreal and NotreDame Hospital, Montreal, Quebec. 
oropharynx, a gauze throat pack was inserted as an added precaution against aspiration of blood.

The operation had proceeded uneventfully for seventy minutes when a modification in tone and sound intensity of the respirator was noted during both respiratory phases; simultaneously, tidal volume was reduced to $100 \mathrm{ml}$ as indicated on the bellows scale. Manual ventilation was immediately attempted but a serious obstruction prevented adequate inflation of the lungs. The throat pack was promptly removed. No defects or kinks were detected in the tracheal tube or breathing tubes. The progress of a polyvinyl suction catheter introduced into the tracheal tube was abruptly arrested at the distal extremity of the tube. Suction was non-productive of either blood clots or mucus plugs. The armoured tube was quickly removed without preliminary deflation of the cuff and was promptly replaced by a polyvinyl chloride orotracheal tube. Manual and automatic ventilation then resumed normally. Normal colour promptly returned following maximal oxygenation and premature ventricular contractions disappeared within one minute. The operative procedure was terminated without further ventilatory problems.

Examination of the tube revealed an enormous bulge at the distal bevelled extremity, where the metal spirals do not extend (Figure 1). The air from the inflated cuff had infiltrated between the two layers of latex which form the nonrigid tongue of the bevelled extremity, thus creating an unsupported inflated extension of the cuff. The inflated flap ballooned out on both sides, causing an almost complete airway obstruction at the bevelled tip of the tube.

When air in the cuff was released, deflation of the ballooned extension flap was very slow. When the cuff was completely collapsed, the tube had a normal appearance; but the bulge in the latex tip could be reproduced easily by reinflation of the cuff.

Due to posture and the presence of drapes the patient's face and breathing tubes were not visible for observation, thus making diagnosis of an insidiously progressive obstruction more difficult. However, early diagnosis was established by increase in heart rate, as observed on the cardioscope; modified cycling sounds in the respirator; prolongation of the inspiratory phase due to increased resistance to inflation and decreased excursion of the respirator bellows.

\section{Discussion}

Stanley ${ }^{1,2}$ observed that tracheal tube cuff volume and pressure nearly doubled in magnitude after one hour of nitrous oxide and oxygen anaesthesia at a concentration of 75 per cent $\mathrm{N}_{2} \mathrm{O}$. He attributed this to diffusion of nitrous oxide and oxygen into the cuff and retention of nitrogen in the cuff. In our case these conditions were duplicated, since respiratory obstruction occurred after one hour of anaesthesia with a mixture of $\mathrm{N}_{2} \mathrm{O}: \mathrm{O}_{2}$ in a proportion of 70 per cent to 30 per cent and a cuff inflated with air. Diffusion of nitrous oxide into the cuff caused increased pressure and excessive stress upon the layered structure of the built-in cuff. These conditions acting upon cuff structure already weakened by previous multiple 
FigunE 1. Anterior view of the bulge at the bevelled extremity where the metal spirals do not extend. The air from the inflated cuff had infiltrated between the two layers of latex creating an unsupported inflated extension of the cuff.

sterilization with ethylene oxide ${ }^{3}$ caused infiltration of nitrous oxide between the two layers of the bevelled extremity of the tube.

Many reports of airway obstruction involving the cuff of armoured tracheal tubes have been published. ${ }^{4-6}$ Review of these reports previous to Stanley's studies fails to involve nitrous oxide diffusion as a possible causative agent in this type of mechanical obstruction. Stanley ${ }^{7}$ recommends that to avoid pneumatic overpressurization and overdistension of tracheal tube cuffs the cuff should be inflated with a sample of the inspired anaesthetic mixture rather than with room air. Another alternative is the incorporation of a pressure-relief valve into the cuff inflating tube which will bleed off excess cuff gases while maintaining adequate minimum occlusive cuff volume. ${ }^{8}$ If room air is used to inflate the cuff, it is impor- 
tant to measure cuff volume changes and to deflate cuffs periodically to avoid build-up of cuff volume during nitrous oxide anaesthesia. ${ }^{7}$

\section{SUMMARY}

The occurrence of an airway obstruction with a cuffed flexometallic tracheal tube is reported. The cause of the obstruction is attributed to internal herniation of the distal extremity of the tube secondary to diffusion of anaesthetic gases into the tracheal tube cuff and subsequently between the two layers of the distal extremity of the tube. Methods to avoid overdistension of the cuff volume are described.

\section{RÉSUMÉ}

On rapporte un cas d'obstruction respiratoire associé à l'usage d'un tube trachéal armé muni d'un ballonnet. L'obstruction fut causée par une hernie interne de l'extrémité distale du tube. La diffusion des gaz anaesthésiques dans le ballonnet d'abord puis entre les deux parois due tube luimême est la cause de cette dilatation aneurysmale du tube. Nous avaons décrit queques méthodes qui nous permettent d'éviter cette augmentation de volume et de pression dans le ballonnet.

\section{REFERENCES}

1. Stanley, T.H. Effects of anaesthetic gases on endotracheal tube cuff gas volumes. Anaesth. Analg. 53: 480-482, 1974.

2. Stanley, T.H., Kawamura, R., \& Graves, C. Effects of nitrous oxide on volume and pressure of endotracheal tube cuffs. Anaesthesiology. 41: 256-262, 1974.

3. Catane, R. \& Davidson, J.T. A hazard of cuffed flexometallic endotracheal tubes. Brit. J. Anaesth. $41: 1086,1969$.

4. Cohen, D.D. \& Dillon, J.B. Hazards of armoured endotracheal tubes. Anaesth. Analg. 51: $856,1972$.

5. Minakhun, R.K. Airway obstruction with cuffed armoured tracheal tubes. Canad. Anaesthe. Soc. J. 21: 251-253, 1974.

6. KoнLI, M.S. \& Manku, R.S. Reinforced endotracheal tube-diversion of air from cuff balloon producing obstruction. Anaesthesiology 27:513, 1966.

7. Stanley, T.H. Nitrous oxide and pressures and volumes of high- and low-pressure endotracheal tube cuffs in intubated patients. Anaesthesiology 42: 637-640, 1975.

8. Stanley, T.H., Foote, J.W., \& Wen-Shin LiU A simple pressure-relief valve to prevent increases in endotracheal tube cuff and volume in intubated patients. Anaesthesiology. 43: 478-481, 1975. 